\title{
SMST 2018: Engaging Our Future
}

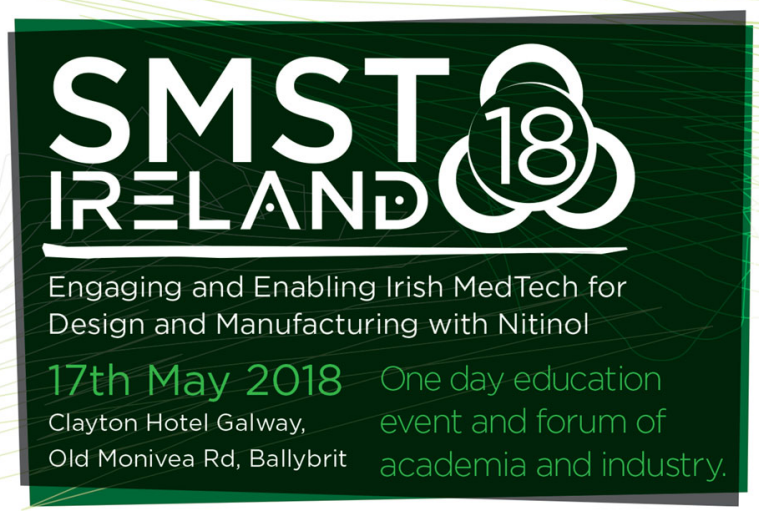

SMST 2018, an exclusive one-day education event, will be held at Clayton Hotel Galway, Ballybrit, Galway, Ireland, on May 17, 2018. This forum of academia and industry will focus on engaging and enabling effective shape memory alloy design in Irish Biotechnology through open communication.

The education workshop topics include History, Advance, State-of-the-Art of SMA \& NiTi, Applications, When NOT to use SMA, and Design for Fatigue. Afternoon industrial and academic short talks will focus on New Applications and Challenges and Solutions in Design with SMA and NiTi from speakers from leading companies and institutions such as Fort Wayne Metals, Biomedical Engineering, Boston Scientific, Cerenovus, Leeds University, and Vascutek.

For additional information and to register, please visit: https://www.asminternational.org/web/smst-2018/home. 